The International Journal of Indian Psychology

ISSN 2348-5396 (e) | ISSN: 2349-3429 (p)

Volume 5, Issue 1, DIP: 18.01.109/20170501

DOI: $10.25215 / 0501.109$

http://www.ijip.in | October-December, 2017

Original Research Paper

\title{
Sexual Dysfunction in Female Patients with Psychiatric Disorders: Women's Mental Health and Sexuality
}

\author{
Dr Nilay Patel ${ }^{1 *}$, Dr Darpan Kaur ${ }^{2}$, Dr Rakesh Ghildiyal ${ }^{3}$
}

\section{ABSTRACT}

Background: Background studies highlight that Sexual dysfunction can be present in patients with psychiatric disorders. Aims \& Objectives To assess profile of sexual dysfunction in female patients with psychiatric disorders. And To assess associated factors in female patients with psychiatric disorders. Material \& Methods: This study was conducted over a period of 3 months at Department of Psychiatry, MGM Medical College. The inclusion criteria comprised of female adult married inpatients referred for psychiatry opinion. The patients were provided standard treatment and were offered to participate in the study. Those who were willing to participate in the study were administered the data collection form comprising of relevant variables. The data collection form comprised of variables such as demographic factors, psychosocial stressors, substance use, medical problems, comorbid psychiatry diagnosis, treatment received, etc. Data was collected on excel sheet and analyzed using SPSS. Institutional Ethics Committee permission was obtained. Results: A total of $n=30$ females fulfilling inclusion criteria were included. The study revealed that sexual dysfunction is prevalent $n=14$ (46.66\%) of female subjects. Sexual problems related to drive were most common and reported in $42.86 \%$ of patients. Sexual problems related to arousal were present in $21.43 \%$ and $21.43 \%$ also reported problems related to orgasm. Overall, the most common psychiatric disorder was Mood disorder present in 36.67\%. Conclusions: We found that prevalence of sexual dysfunction was $46.66 \%$ in our study. We suggest that sexual dysfunction can exist in female patients with psychiatric disorders and appropriate awareness and relevant clinical management may be considered.

\section{Keywords: Sexual Dysfunction, Female Patients, Psychiatric Disorders}

Female sexual dysfunction can drastically diminish quality of life for many women. It is estimated that in the United States $40 \%$ of women have sexual complaints. These conditions are frequently under diagnosed and undertreated. ${ }^{[1]}$ Diagnostic evaluation is based on an indepth sexual history, including sexual and gender identity and orientation, sexual activity and

\footnotetext{
${ }^{1}$ PG Resident, Department of Psychiatry, MGM Medical College, Navi Mumbai, India

2 Associate Professor, Department of Psychiatry, MGM Medical College, Navi Mumbai, India

${ }^{3}$ Professor and HOD, Department of Psychiatry, MGM Medical College, Navi Mumbai, India *Responding Author

(C) 2017 Patel N, Kaur D, \& Ghildiyal R; licensee IJIP. This is an Open Access Research distributed under the terms of the Creative Commons Attribution License (www.creativecommons.org/licenses/by/2.0), which permits unrestricted use, distribution, and reproduction in any Medium, provided the original work is properly cited.
} 


\section{Sexual Dysfunction in Female Patients with Psychiatric Disorders: Women's Mental Health and Sexuality}

function, current level of sexual function, overall health and comorbidities, partner relationship and interpersonal factors, and the role of cultural and personal expectations and attitudes $^{[2]}$

Research strongly supports the routine clinical investigation of psychological factors, partnerrelated factors, context, and life stressors. Psychological, interpersonal, and sociocultural factors play a significant role in making one vulnerable to developing a sexual concern, in triggering the onset of a sexual difficulty, and in maintaining sexual dysfunction in the long term. ${ }^{[3]}$ The incidence and prevalence of various sexual dysfunctions in women and men are important to understand to designate priorities for epidemiologic and clinical research. ${ }^{[4]}$ Sexuality is an important aspect of the personality of an individual and influences psychological, physical and social well-being of both men and women. There is a lack of research publications and sexuality related literature. ${ }^{[5]}$

\section{Aims and objectives of the study:}

- To assess profile of sexual dysfunction in female patients with psychiatric disorders.

- To assess associated factors in female patients with psychiatric disorders.

\section{METHODOLOGY}

This study was conducted over a period of 3 months at Department of Psychiatry, MGM Medical College. The inclusion criteria comprised of female adult married inpatients referred for psychiatry opinion. The patients were provided standard treatment and were offered to participate in the study. Those who were willing to participate in the study were administered the data collection form comprising of relevant variables. Those female patients who were less than 18 years, single, or severely medically or having very severe psychiatric illness rendering them uncooperative for assessment were excluded from the study. The data collection form comprised of variables such as demographic factors, psychosocial stressors, substance use, medical problems, comorbid psychiatry diagnosis, treatment received, etc. Data was collected on excel sheet and analyzed using SPSS. Institutional Ethics Committee permission was obtained.

\section{RESULTS}

A total of $n=30$ females fulfilling inclusion criteria were included. The mean age of the sample was 34.19 years (SD 6.76). The study revealed that sexual dysfunction is prevalent $\mathrm{n}=14(46.66 \%)$ of female subjects. Sexual problems related to drive were most common and reported in $42.86 \%$ of patients. Sexual problems related to arousal were present in $21.43 \%$ and $21.43 \%$ also reported problems related to orgasm. Sexual problems related to pain were present in $14.28 \%$ of patients. Fifty four percent of patients had medical problems such as diabetes, hypertension, cardiac problems, thyroid dysfunction, etc. We also found that stressors were present in 63.33 percent of patients with interpersonal stressors as most common in $44.39 \%$ of patients. Overall, the most common psychiatric disorder was Mood 
disorder present in $36.67 \%$. Antidepressants were the most common medications in $43 \%$ of the sample.

Table 1: Age profile of the sample

\begin{tabular}{|l|l|l|l|l|l|}
\hline & $\mathbf{N}$ & Minimum & Maximum & Mean & Std. Deviation \\
\hline Age & 30 & 18 & 55 & 34.19 & 6.761 \\
\hline
\end{tabular}

Graph 1: Profile of sexual problems :

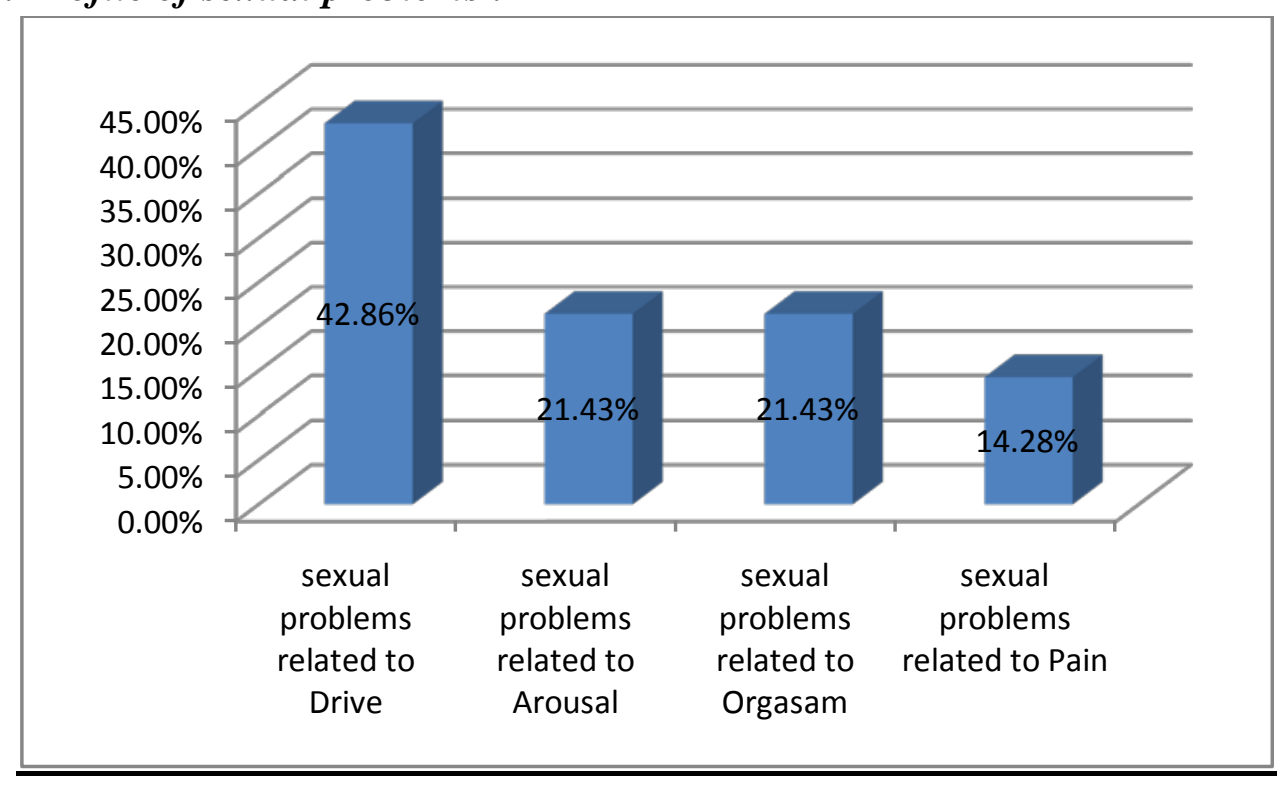

Graph 2 Profile of Psychiatric Diagnosis:

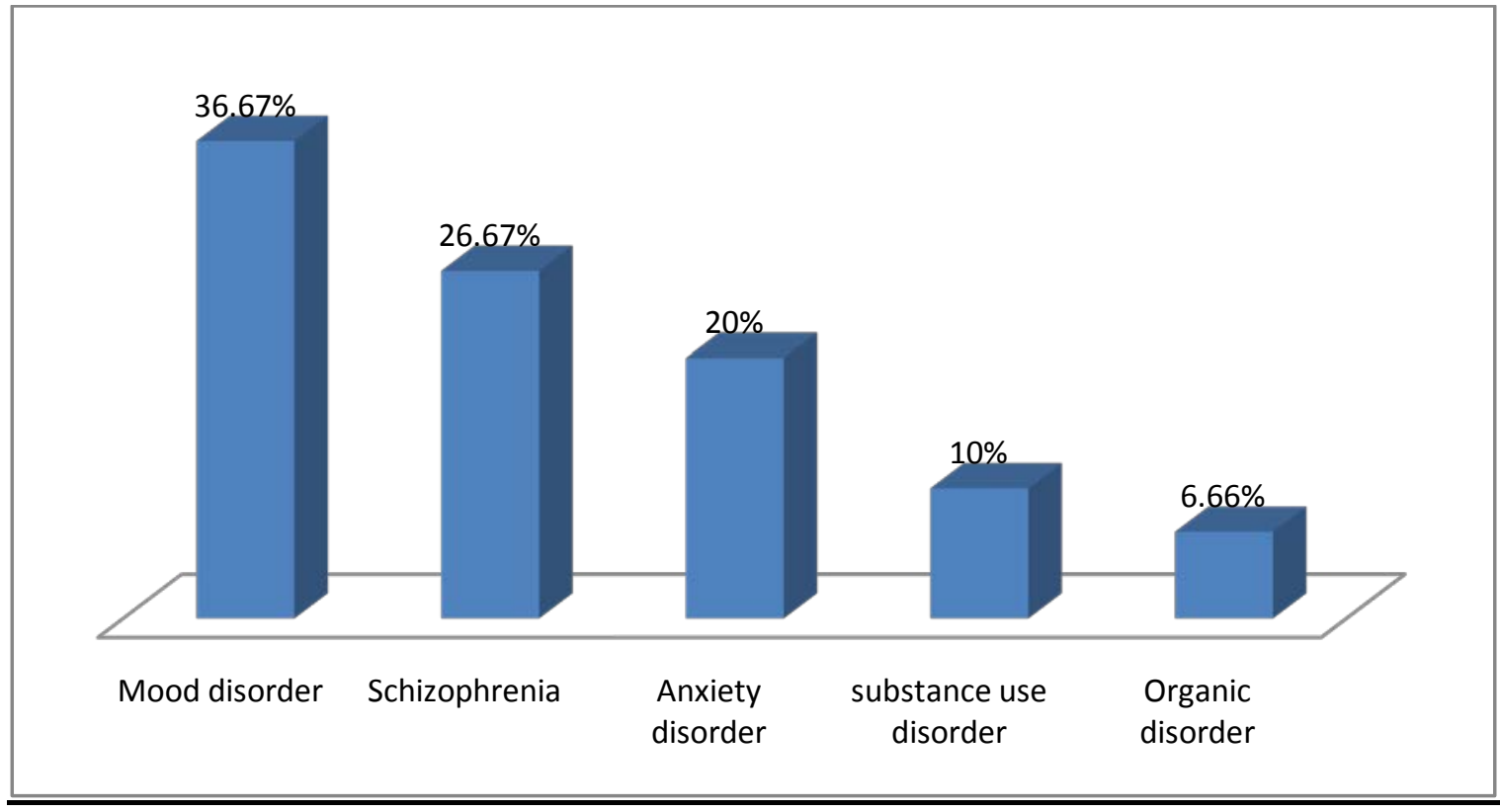

(C) The International Journal of Indian Psychology, ISSN 2348-5396 (e)| ISSN: 2349-3429 (p) | 83 


\section{Graph 3 Profile of psychiatric medications:}

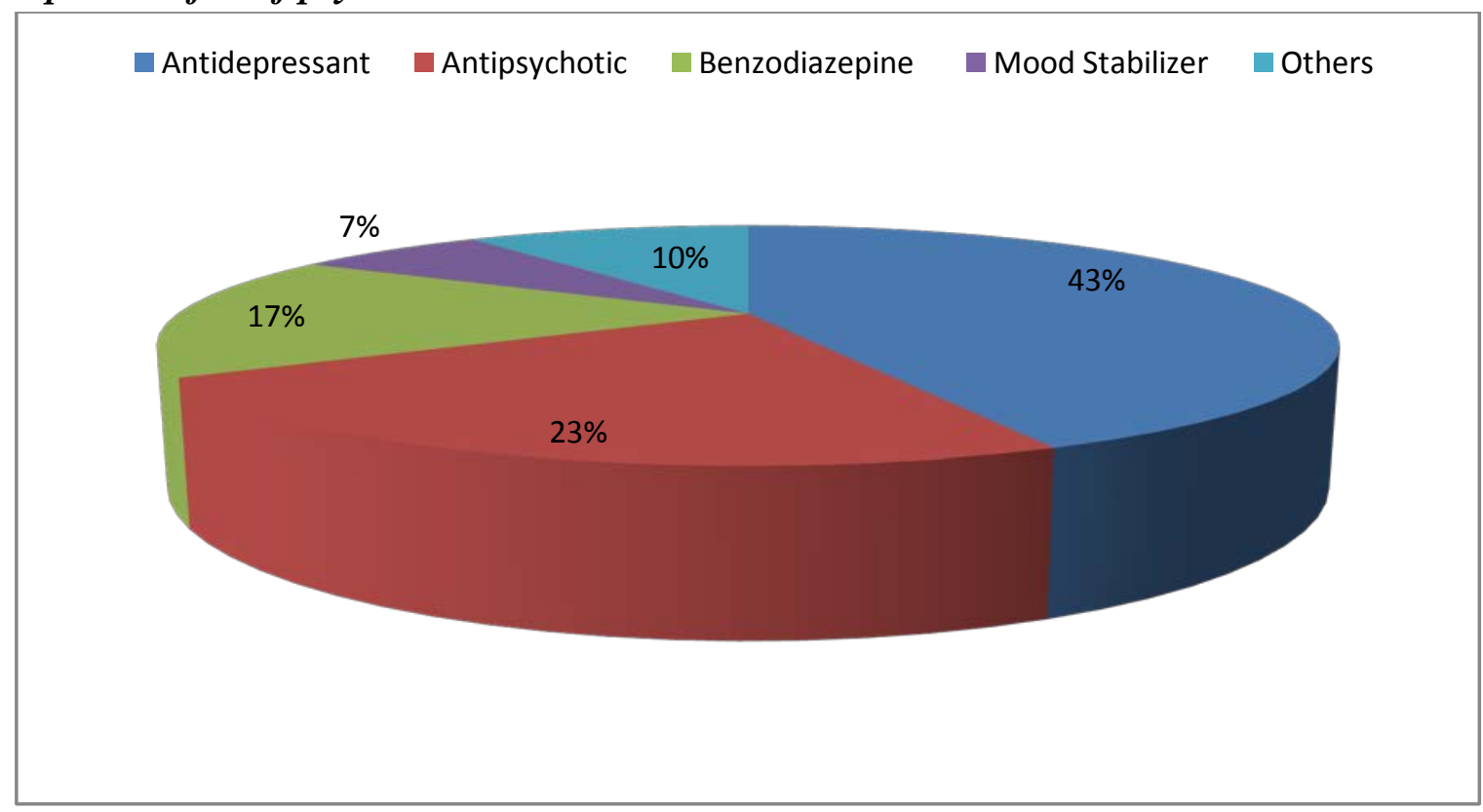

\section{DISCUSSION}

$\mathrm{Bn} \mathrm{AK}$ et al found that Low educational qualification, initiation of alcohol at earlier age, longer duration of alcohol consumption and dependence and severe dependence appeared to be the most significant predictors of developing Sexual dysfunction. ${ }^{[6]}$ Depression with medical comorbidities was associated with a significant decrease in desire. ${ }^{[7]}$ Simiyon $\mathrm{M}$ et al found that Negative symptoms scale of schizophrenia and side effects such as weight gain, menstrual disturbances, galactorrohea and dry vagina were significantly associated with Female Sexual Dysfunction. ${ }^{[8]}$ Research has shown that young adults with psychotic disorders frequently have problems relating to sexuality, intimacy and relationships. [9] Sexual dysfunction following trauma exposure may be mediated by PTSD-related biological, cognitive, and affective processes. $\left.{ }^{[10}\right]$ Viswanathan $S$, et al found that the prevalence of sexual dysfunction, based on the cut-off score on the FSFI, was 64.3\%. However, only a minority of women considered it a problem (4.7\%), expressed dissatisfaction (5.8\%) or sought medical help (2.5\%). The most common explanatory models offered for sexual problems included an unhappy marriage, stress and physical problems. ${ }^{[11]}$ Women with schizophrenia have a better social outcome, longer lasting (sexual) relationships, and more offspring than men with schizophrenia. Although patients consider sexual problems to be highly relevant, patients and clinicians not easily discuss these spontaneously, leading to an underestimation of their prevalence and contributing to decreased adherence to treatment. ${ }^{[12]}$

Obtaining sufficient sleep is important to the promotion of healthy sexual desire and genital response, as well as the likelihood of engaging in partnered sexual activity. [13] Park JE found that a relatively lower prevalence of sexual dysfunction than previously reported, but supports its strong association with psychiatric disorders among postmenopausal women. ${ }^{[14]}$ Hypertensive patients exhibit an elevated presence of sexual 


\section{Sexual Dysfunction in Female Patients with Psychiatric Disorders: Women's Mental Health and Sexuality}

dysfunction, as well as anxious and depressive symptoms. Sexuality is an important element in patient quality of life, and a broad understanding of female sexual function is fundamental for good follow-up in these patients. ${ }^{[15]}$ Elyasi $\mathrm{F}$ et al found the prevalence of sexual dysfunction was $78.7 \%$ and found high prevalence of sexual dysfunction in diabetic women, especially among those complaining depression. ${ }^{[16]}$ The acknowledgement and management of sexual dysfunction in patients with schizophrenia by clinicians may be important for improvement of their quality of life and adherence to medication. ${ }^{[17]}$ Loss of desire is underrecognized as a symptom of disease or as a complaint in its own right. As further developments in treatment options, both therapies based and pharmacological, are made, it is increasingly important that clinicians enquire about sexual dysfunction, including loss of desire, at every consultation. ${ }^{[18]}$ All antidepressants with serotonergic activity can cause mild to severe sexual dysfunction such as decreased libido and delayed orgasm frequently ( $>60 \%)$ or anorgasmia and arousal difficulties sometimes (30\%). Antipsychotics that highly increase prolactin levels and strongly block dopamine receptors could be related to sexual dysfunction as well. ${ }^{[19]}$ Depressive symptoms and depressive illness are associated with impairments in sexual function and sexual dissatisfaction in untreated and treated patients. Most currently available antidepressant drugs are associated with development or worsening of sexual dysfunction in a substantial proportion of patients. ${ }^{[20]}$ Following the onset of depression, the incidence of sexual dysfunction started at an early age in women. ${ }^{[21]}$ High rate of sexual dysfunction was reported in the majority of patients with schizophrenia and given its negative impact on social adjustment, QOL and treatment adherence, efforts should be made to address sexual dysfunction in this patient population. ${ }^{[22]}$ Screening for sexual problems and consideration of contributing factors such as neurobiology, reproductive life events, medical problems, medication use, and depression can help guide appropriate treatment and thereby improve the sexual functioning and quality of life of affected women. [23] McCabe MP et al found that for women and men, diabetes, heart disease, urinary tract disorders, and chronic illness were significant risk factors for sexual dysfunction. Depression and anxiety and the medications used to treat these disorders also were risk factors for sexual dysfunction in women and men. In addition, substance abuse was associated with sexual dysfunction. ${ }^{[24]}$

Psychosocial variables, such as availability of a partner, relationship quality, and psychological functioning, also play an integral role. Future directions for research should include deepening our understanding of how sexual function changes with aging and developing safe and effective approaches to optimizing women's sexual function with aging. ${ }^{[25]}$ Shetageri VN et al found that Sexual Dysfunction was prevalent in more than $50 \%$ of female patients on psychotropic drugs. ${ }^{[26]}$ Adverse sexual effects can be complex because there are several potentially overlapping etiologies, including sexual dysfunction associated with the underlying mood disorder. ${ }^{[27]}$ Grover S, et al found that approximately one third of the patients receiving lithium experience sexual dysfunction, and it is associated with poor medication adherence. ${ }^{[28]}$ Grover $\mathrm{S}$ et al found that sexual dysfunction is quite prevalent in married female patients receiving antidepressants and all the domains of sexual functioning 


\section{Sexual Dysfunction in Female Patients with Psychiatric Disorders: Women's Mental Health and Sexuality}

are impaired by antidepressants. ${ }^{[29]}$ Shame, stigma, cultural barrier, lack of knowledge, attitudinal influences, misconceptions, and counter transference can exist in Indian scenario and sexual dysfunction is a culture sensitive issue. ${ }^{[30]}$ There is a paucity of literature on management issues with an emergent need to conduct systematic studies in this neglected area so that the concerns of these patients can be properly dealt with. ${ }^{\text {[31] }}$

\section{CONCLUSION}

We found that prevalence of sexual dysfunction was $46.66 \%$ percent in our study. The strengths of our study being that we have attempted to study the profile of sexual dysfunction in patients with psychiatric disorder which is very important and relevant to our setting in view of scarce studies from developing countries such as India. The limitations of study are that it is a small sample size and we have not used any validated rating scale and we have not correlated the type of medication, dosages and the psychiatric diagnosis with sexual dysfunction in view of a smaller study size. We suggest that further studies in future may look into these factors and conduct studies with larger sample size over a longer period. We suggest that sexual dysfunction can exist in female patients with psychiatric disorders and appropriate awareness and relevant clinical management may be considered.

\section{Acknowledgments}

The author appreciates all those who participated in the study and helped to facilitate the research process.

\section{Conflict of Interest}

There is no conflict of interest of the authors with anyone regarding financial matters.

\section{REFERENCES}

1.Clayton AH, Valladares Juarez EM. Female Sexual Dysfunction. Psychiatr Clin North Am. 2017 Jun;40(2):267-284.

2. Hatzichristou D, Kirana PS, Banner L, Althof SE, Lonnee-Hoffmann RA, Dennerstein L, Rosen RC. Diagnosing Sexual Dysfunction in Men and Women: Sexual History Taking and the Role of Symptom Scales and Questionnaires. J Sex Med. 2016 Aug; 13(8):1166-82.

3. Brotto L, Atallah S, Johnson-Agbakwu C, Rosenbaum T, Abdo C, Byers ES, Graham C, Nobre P, Wylie K. Psychological and Interpersonal Dimensions of Sexual Function and Dysfunction. J Sex Med. 2016 Apr;13(4):538-71.

4. McCabe MP, Sharlip ID, Lewis R, Atalla E, Balon R, Fisher AD, Laumann E, Lee SW, Segraves RT. Incidence and Prevalence of Sexual Dysfunction in Women and Men: A Consensus Statement from the Fourth International Consultation on Sexual Medicine 2015. J Sex Med. 2016 Feb;13(2):144-52.

5. Sathyanarayana Rao TS, Darshan MS, Tandon A. An epidemiological study of sexual disorders in south Indian rural population. Indian J Psychiatry. 2015, AprJun;57(2):150-7. 
6. Bn AK, M S, J SR, Dr P. Sexual dysfunction in women with alcohol dependence syndrome: A study from India. Asian J Psychiatr. 2017 Aug; 28:9-14.

7. K Sreelakshmy,Velayudhan R, Kuriakose D, Nair R. Trends Psychiatry Psychother 39 (2), 106-109. Apr-Jun 2017.

8. Simiyon M, Chandra PS, Desai G. Sexual dysfunction among women with SchizophreniaA cross sectional study from India. Asian J Psychiatr. 2016, Dec;24:93-98.

9. de Jager J, Wolters HA, Pijnenborg GH. [Young adult with psychotic disordershave problems relating to sexuality, intimacy and relationships. An explanatorystudy based on focus group]. Tijdschr Psychiatr. 2016;58(3):223-7.

10. Yehuda R, Lehrner A, Rosenbaum TY. PTSD and Sexual Dysfunction in Men and Women. J Sex Med. 2015 May;12(5):1107-19.

11. Viswanathan S, Prasad J, Jacob KS, Kuruvilla A. Sexual function in women in rural Tamil Nadu: disease, dysfunction, distress and norms. Natl Med J India. 2014 JanFeb; 27(1):4-8.

12. de Boer MK, Castelein S, Wiersma D, Schoevers RA, Knegtering H. The facts about sexual Dysfunction in schizophrenia: an overview of clinically relevant findings. Schizophr Bull. 2015 May;41(3):674-86.

13.Kalmbach DA, Arnedt JT, Pillai V, Ciesla JA. The impact of sleep on female sexual response and behavior: a pilot study. J Sex Med. 2015 May;12(5):1221-32.

14. Park $\mathrm{JE}^{1}$, Sohn $\mathrm{JH}^{1}$, Seong $\mathrm{SJ}^{2}$, Cho $\mathrm{MJ}^{1}$.Prevalence of Sexual Dysfunction and Associations with Psychiatric Disorders Among Women Aged 50 and Older. J Womens Health (Larchmt). 2015 Jun;24(6):515-23.

15. Nascimento ER, Maia AC, Nardi AE, Silva AC. Sexual dysfunction in arterial hypertension women: The role of depression and anxiety. J Affect Disord. 2015 Aug, 1;181:96-100.

16. Elyasi F, Kashi Z, Tasfieh B, Bahar A, Khademloo M. Sexual dysfunction in women with type 2 diabetes mellitus. Iran J Med Sci. 2015 May; 40(3):206-13.

17. Lee JY, Kim SW, Lee YH, Kang HJ, Kim SY, Bae KY, Kim JM, Shin IS, Yoon JS.Factors associated with self-rated sexual function in Korean patients with schizophrenia receiving risperidone monotherapy. Hum Psychopharmacol. 2015 Nov;30(6):416-24.

18. Holloway V, Wylie K. Sex drive and sexual desire. Curr Opin Psychiatry. 2015, Nov;28(6):424-9.

19. Montejo AL, Montejo L, Navarro-Cremades F. Sexual side-effects of antidepressant and antipsychotic drugs. Curr Opin Psychiatry. 2015 Nov; 28(6):418-23.

20. Baldwin DS, Manson C, Nowak M. Impact of Antidepressant Drugs on Sexual Function and Satisfaction. CNS Drugs. 2015 Nov;29(11):905-13.

21 Roy P, Manohar S, Raman R, Sathyanarayana Rao TS, Darshan MS. Female sexual dysfunction: A comparative study in drug naive 1(st) episode of depression in a general hospital of South Asia. Indian J Psychiatry. 2015 Jul-Sep;57(3):242-8.

22. Hou CL, Zang Y, Rosen RC, Cai MY, Li Y, Jia FJ, Lin YQ, Ungvari GS, Ng CH, Chiu HF, Xiang YT. Sexual dysfunction and its impact on quality of life in Chinese 
patients with schizophrenia treated in primary care. Compr Psychiatry.2016 Feb;65:116-21.

23. Clayton AH, Harsh V. Sexual Function Across Aging. Curr Psychiatry Rep. 2016 Mar;18(3):28. doi: 10.1007/s11920-016-0661-X.

24. McCabe MP, Sharlip ID, Lewis R, Atalla E, Balon R, Fisher AD, Laumann E, LeeSW, Segraves RT. Risk Factors for Sexual Dysfunction Among Women and Men: A Consensus Statement From the Fourth International Consultation on Sexual Medicine 2015. J Sex Med. 2016 Feb;13(2):153-67.

25. Thomas HN, Thurston RC. A biopsychosocial approach to women's sexual function and dysfunction at midlife: A narrative review. Maturitas. 2016 May;87:49-60.

26. Shetageri VN, Bhogale GS, Patil NM, Nayak RB, Chate SS. Sexual Dysfunction among Females Receiving Psychotropic Medication: A Hospital-based Cross-sectionalStudy. Indian J Psychol Med. 2016 Sep-Oct;38(5):447-454.

27. Lorenz T, Rullo J, Faubion S. Antidepressant-Induced Female Sexual Dysfunction. Mayo Clin Proc. 2016 Sep;91(9):1280-6.

28. Grover S, Ghosh A, Sarkar S, Chakrabarti S, Avasthi A. Sexual dysfunction in clinically stable patients with bipolar disorder receiving lithium. J Clin Psychopharmacol. 2014 Aug;34(4):475-82.

29. Grover S, Shah R, Dutt A, Avasthi A. Prevalence and pattern of sexual dysfunction in married females receiving antidepressants: An exploratory study. J Pharmacol Pharmacother. 2012 Jul;3(3):259-65.

30. Kaur D, Jyothy KS, Dere S, Nebhinani N, Ajinkya S. Workshop. Indian J Psychiatry 2014;56, Suppl S1:16-8.

31. Prakash O, Rao TS. Sexuality research in India: An update. Indian J Psychiatry. 2010 Jan;52(Suppl 1):S260-3.

How to cite this article: Patel N, Kaur D, \& Ghildiyal R (2017). Sexual Dysfunction in Female Patients with Psychiatric Disorders: Women's Mental Health and Sexuality. International Journal of Indian Psychology, Vol. 5, (1), DIP: 18.01.109/20170501, DOI: $10.25215 / 0501.109$ 